\title{
Sense of place in children's residential care homes: perceptions of home?
}

\author{
Clark, A., Cameron, C. \& Kleipoedszus, S.
}

\begin{abstract}
How do young people living in residential care perceive their environment? How do they experience the sights, sounds, smell and feel of living in an institution? How may attachment to place contribute to the wellbeing of young people? This paper explores meanings of home in domestic and regulated (institutional) environments from the perspective of young people and staff living and working in a residential children's home in England. Drawing on a pilot study using visual participatory research methods adapted from the Mosaic approach (Clark 2011), the study identifies what young people and staff considered important about the place where residents lived. Using photographs and commentary, three conceptual themes are discussed: the home as institutional space; the home as 'practices'; and home as idealised space. The paper raises questions as to how ways of 'doing home' can be supported in these liminal spaces that strive to be both domestic and institutional.
\end{abstract}

\section{Keywords}

Space, home, meaning-making, visual participatory methods

\section{Corresponding author:}

Claire Cameron Reader in Education, Thomas Coram Research Unit, Institute of Education University of London 27/28 Woburn Square, London WCIH OAA

C.cameron@ioe.ac.uk

\section{Introduction}

What meanings do young people in residential care attach to the space where they are living? While there is, over time, an appeal to home and homeliness in English policy and practice, is there in fact a deep ambivalence about the sense of place as home? To what extent is the space not a home but still an institution? Or is it possible to combine both 'home' and 'institution' in the sense of place that is residential care?

The aim of this paper is to explore meanings of home in domestic and regulated (institutional) environments from the perspective of young people and staff living and working in a residential children's home in England. We start by reviewing conceptualisations of the physical environment of residential children's homes before examining meanings of home more broadly. We raise the issue of tension between the 
domestic and the institutional place, and what the impact of using the term 'home' to describe residential care places might be on the role and task of the institution.

We then describe a pilot study conducted in England that used an adaptation of the Mosaic approach (Clark \& Moss, 2001, Clark 2010; Clark, 2011) using participatory visual methods to identify what young people considered important about the place where they were living. The analysis focuses on findings from three images: the institutional space of home; the home as 'practices'; and home as idealised space. We draw attention to examples given by young people and staff of objects and places that are associated with a sense of home. We raise questions as to how ways of 'doing home' can be supported in these liminal spaces that strive to be both domestic and institutional.

Working with notions of 'space' and 'place' begs the question of definition. There are common, everyday definitions (Tuan, 1977), and distinctions between the terms usually rest on the extent to which 'place' is invested with meaning while 'space' is seen as more abstract (Clark \& Gallacher, 2013). Working at the intersection of disciplines, as is the case here, lends a complexity to the definitions. From the perspective of human geography, Massey (2005, p.130), whose work on defining space and place has been widely influential, argues that places are not points or areas on a map, but integrations of space and time, or 'spatio-temporal events'. So the experiences of young people in a residential home represents a particular integration of space and time, and one that draws attention to the specifity of place. Clark and Gallacher $(2013$, p.5) cite, as an example of integrated space and time, a box, in a London underground station, that represented a regular meeting place for schoolgirls on their way home from school to share stories, such that 'the box became a significant landmark in the shared childhoods' of these young people. On the other hand, from a sociology of childhood perspective, Moss and Petrie (2002, p.9) argue that 'the concept of children's spaces understands provisions as environments of many possibilities - cultural and social, but also economic, political, ethical, aesthetic, physical - some predetermined, others not, some initiated by adults, others by children'. In this interpretation, space is a lived, interpreted arena of 'possibilities and potentials' ... public places for children to live their childhoods' (ibid).

In this paper, we take our inspiration from both perspectives. We define place as the physical environment that is invested with meaning through the interactions of children and adults within them, meanings that may change through the interactions and understandings of social actors. We are concerned with 'home' as an example of 'place' that is invested with meaning for children in residential care.

\section{Place and home in residential care}

\section{The use of 'place' in residential care theory}

Since 1948, English policy for residential care homes for children and young people who live away from their birth parents has had an ambition to be small scale, with trained staff and a focus on individuals. The environment was to be 'as much like [that] other children [experience] as possible' (Kahan 2000, np). In the linking of place (residential home) and quality of experience, the policy effort appeared to be to emulate normative understandings of childhood environment - based on 'home'. 
However, little attention has been given in residential care theory to the role of the physical environment in young people's wellbeing; much more has been given to the relational environment (Jack, 2010). Two main lines of thinking about residential care are psychodynamic theory and behaviourist theory (Smith, 2009). Psychodynamic theories informed the development of planned environment therapy, where the material boundaries or milieu forms a physical representation of 'containment' or emotional security (Kornerup, 2009; Steckley, 2012). Behaviourist theories do not discuss the role of the physical environment in children's wellbeing at all. A third, less well known in the UK, line of thinking, is a broadly conceptualised learning approach called 'group care' (Maier, 1987). Maier draws attention to the importance of the person's wellbeing in the whole environment, also known as the 'lifespace', including the group, sustaining bodily comfort, private or personal space, rhythms of life and creating predictability and dependability in everyday life. He argues that physical space is not only divided into public and private spaces, but that spatial alterations have implications for behaviour, and signals of professional practice. For example, using the office to complete paperwork also serves as an opportunity to 'hide' from residents. For both residents and staff, the opportunity to have private space and time is 'a human requirement' (Maier, 1987, p. 62). Moreover, the conception of 'public' space in residential care homes needs to consider which public - the children, the staff, visiting professionals, parents or other visitors? Overall, Maier concludes that physical space has an important contribution to make to a sense of wellbeing and belonging, in that deprivation of comfort, privacy and sociability in spaces will lead to adverse outcomes for young people.

\section{The place of home in residential care}

The majority of young people living in residential care in England are aged 10 -18 years of age with a median age of around 15 years. They are likely to be in a placement for around ten months (Berridge et al., 2012), and to have had one or more placements away from birth parents before arriving in residential care. Most of the young people will have one of three sets of needs: care for a short period and with straightforward needs; complex or chronic needs for specialist care due to abuse and neglect by birth parents; or extensive and enduring needs due to serious abuse including violence and requiring therapy of some kind (Clough, Bullock \& Ward, 2006). The question arises as to whether and how the domestic imagery of 'home' serves a purpose for this group of young people. In the 1960s, the residential care task was defined as threefold: nurturing; dealing with loss; and helping children manage their behaviour (Kahan \& Banner, 1969). Around the same time, there was a deliberate appeal to a sense of place as home in the development of 'family group homes' in England, by way of contrast with more prevalent larger and more impersonal institutions. Family group homes were designed to be no larger than that of an ordinary family, usually headed by the wife of a married couple, who lived in an adjacent apartment, staffed by assistants who 'lived in' and often sited where they could blend into ordinary housing, such as council estates (Lane, 2010). These homes consciously followed a normative domestic family ideology, but, by 1980, almost no staff lived in such homes and for adults, the residential home was a place of work. A general move to smaller-scale homes followed, and, arguably, the sense of place as home became less dependent on the domestic, familial imagery of two parents and long(er) term residents 
living together, and more clearly characterised as a workplace for staff, a temporary home for residents and governed by externally and internally generated institutional rules.

In a Scottish study of the organisation and consumption of food in residential care, Dorrer et al. (2010) found that perceptions of 'homeliness' were highly valued. For staff, a principal representation of homeliness was the practice of eating together; they believed this facilitated or symbolised ideas of togetherness associated with a family home. The young people in the study had rather more complex ideas about whether the home was a home for them. They were much less concerned about food per se and more about using the home as a safe space. Mealtimes and food were used by staff as a means to regulate everyday life through expected sequences of eating, chores, and, last, free time. They were used as a means to establish hierarchies of control, through practices such as locking the kitchens and controlling access to food between meals. For young people, the rules governing the scheduling of the day were emblematic of institutional life, while flexibility and negotiation were signals that the home was 'their place'. Dorrer et al. (2010) identified three spaces within the residential care home they studied: a home, an institution and a workplace. In each, different rules and expectations applied.

The place of home in residential care remains ambivalent. The task of English residential care shifts between (largely) temporary accommodation and treatment or therapy of some kind with escalating severity of needs particularly around attachment difficulties. An appeal to the normative domestic space of home is not to the fore; more important is nurturing effective relationships. Official guidance (National Institute for Health and Clinical Excellence, 2010, p.11) refers to the importance of a sense of belonging as part of emotional wellbeing but reference to place is only implied: it states that placements should 'encourage warm and caring relationships between child and carer that nurture attachment and create a sense of belonging so that the young person feels safe, valued and protected', and 'support the child or young person to participate in the wider network of peer, school and community activities to help build resilience and a sense of belonging'. National Minimum Standards, against which all registered children's homes are inspected, state that space should be adequate and suitable in order to access facilities that promote development. In particular, the environment should be 'comfortable and homely', 'well-maintained and decorated'; 'avoidable hazards are removed as is consistent with a domestic setting', and 'risk reduction does not lead to an institutional feel' (DFE, 2012, p.22). The sentiment is one of promoting a domestic-type environment with an appeal to 'home' as opposed to 'institution', yet the institutional framework is specified in advance and from outside the home. These regulations are in line with the wishes of young people consulted by the English Children's Rights Director (Morgan, 2009). Survey respondents said they valued spaciousness, privacy, a sense of security and a homely feel, and disliked rules that forbade them to enter certain areas of the building, such as the kitchen, kept certain doors locked or used official notices such as 'fire escape' that signalled 'institution'. The task is thus to better understand the sense of home in order to contribute to the improvement of professional and institutional practices.

We now examine some broader definitions of home in order to understand some of the inherent difficulties in creating a 'sense of home' in an institution. 


\section{A Sense of Home}

Home is an ambiguous concept that is open to a range of disciplinary and personal meanings. It may be understood as a physical location, or locations rooted to a particular environment or be more associated with feelings and practices (Mallett, 2008). Here we explore three aspects of home with particular relevance to residential care: the links between home and identity, home as itinerant domesticity and home and homeliness.

\section{Home and identity}

Milligan $(2003,2005)$ emphasises that home is as much a social and emotional concept as a physical one. These social and emotional connections strengthen the link between home and identity. Varley (2008) draws on the work of the political philosopher Iris Marion Young to examine the ways in which these connections may be forged. Young indicates how 'home materialises identity' (Young, 1997, pp.150-151) in two important ways: through the body and through narrative.

Firstly, the link between home and identity is forged through the physical engagement with the spaces, places and objects within a home. Young describes these actions as 'pathways of habit' (Young, 1997, p.150)

Habit memories....memories formed by slow sedimentation and realised by the reenactment of bodily motions ... [from which]... we get our bearings.

Secondly, Young proposes that home 'materialises identity' through the stories that are associated with or contained within the objects in a home: 'without such anchoring of ourselves in things we are literally lost' (Young, 1997, p.151).

If home and identity are understood to be closely linked, then the way rooms are arranged and objects displayed may be one route to understanding how individuals feel about themselves. Hurdley (2006) explored this relationship between domestic display and identity in her study of personal accounts of home interiors. She used the mantelpiece, the shelf above a fireplace, as a framing device for asking individuals what objects they chose to display there and why. Hurdley found that an individual's sense of self and the self-representation of others revealed through the narratives they attached to objects displayed on mantelpieces. Hurdley (2006, p.723) comments: 'The meaning of things in the home is what gives home its meaning'. This would suggest that to be 'homelike', residential care needs to pay attention to the selection of objects for display and the ways in which they are displayed.

\section{Home as itinerant domesticity}

The discussion so far about a sense of home suggests a stable relationship between home and self, slowly accrued over time and embedded in the rooms, objects and displays that exist. However, for many groups of individuals, including young people living in a residential care home, their personal circumstances do not support this continuous relationship. They may have experienced a rapid succession of residences and have had limited opportunity to establish a deep-rooted connection with a space. These young people may have established 'pathways of habit' associated with a particular location and 
objects that act as 'retainers of narratives' but these feelings are likely to be separated from the institutional environment. Das, Ellen and Leonard (2008) explored the sense of home experienced by vulnerable groups and proposed a definition of home as 'modalities' or forms of doing or practices rather than a fixed domestic location. These connections may be spread across a range of sites:

There is a duality of intimacy and alienation as constant moves from and to the home engender an itinerant domesticity and life is lived in the interstices of the house, the prison, the street and various foster homes in which children grow up. (Das et al., 2008, p.352)

This suggests that young people in residential care may experience the residential home as an in-between space dependent on establishing temporary routines of 'doing home'.

\section{Home and homeliness}

A sense of home in an institutional context can be associated with understandings of homeliness, and homemaking. Peace and Holland (2001, p.407) explored the concept of 'homely' within small-scale residential care for older people. They identified three interrelated issues of scale, informality and physical appearance: 'but, as a result of the demands of professional caring and public accountability, it is constantly under pressure to move towards more formality and organised living.' In an earlier paper, Peace and Holland (1998) identified a number of influences or dimensions when discussing the balance between domestic (or homely) and institutional in the residential care homes they investigated. These dimensions are shown in Table 1.

\begin{tabular}{|ll|}
\hline Domesticity & Institutionalisation \\
\hline Privacy & Surveillance \\
\hline Informality & Regulation \\
\hline Risk & Security \\
\hline Normalisation & Specialisation \\
\hline Personal & Professional \\
\hline
\end{tabular}

Table 1 The balance between domestic and institutional influences in small home care settings Source: Holland and Peace (1998) Homely Residential Care.

The dimensions Peace and Holland (2001) draw out in relation to homely care for older people in residential care have distinct commonalities with those raised in relation to residential care for young people. For example, informality was identified as one feature of homeliness that was balanced against regulation. In both settings, there may be practices within the home that may be seen to be constrained by the regulatory framework within which they operate. In the Peace and Holland study, homeliness was also related to the physical appearance of the interiors, including the type of furnishings used, the décor and the objects chosen. They state:

On the whole the furniture and objects such as pictures and ornaments in the day and dining areas belonged to the proprietors, with residents' belongings generally confined to their own rooms. They looked homely - but the question remains, 'whose home?' Shared areas were clearly dominated by the proprietors, subject to the proprietor's notions of acceptable behaviour, and marked by the proprietor's 
taste in furnishings and décor: even in homes with a separate lounge for residents (Peace and Holland, 2001, p.401-402).

The pilot project discussed below picks up on and explores further some of the tensions that Peace and Holland raise, particularly the tensions between informality and regulation and the physical appearance of personal and shared areas.

\section{The Pilot Project}

The Taking Place Seriously pilot project took place in England and Scotland in 2011. The aim was to examine the use and perception of place held by those living and working in one residential care home in each country and to draw some comparative conclusions that would assist in the design of a substantive study. This paper focuses on the data collection in the home in England. The home selected for this pilot study had been involved in an earlier practice development programme with some members of the research team (Cameron et al., 2011) and was known to be interested in research. There was also some familiarity with using photography due to a recent appointment of a learning mentor, who was using photography in her work with young people. The children's home, run by a national charity, had capacity for five residents aged $12-17$. The building was a large freestanding house in a quiet neighbourhood on the edge of a small market town, converted for use as a residential children's home in 2008. Each resident had their own bedroom and bathroom, and downstairs there was a living room, play room, kitchen-dining room and staff offices. To the rear there was a very large garden. There was a staff team of 15 , supervised by the home's manager, the organisation's area manager, and the training and support services of the charity.

\section{Methods}

\section{Identifying methods}

This pilot study set out to identify methods that would enable young people and staff to explore their views and feelings about the physical and social environment of a residential care home. There has been an increasing number of studies that have included photography in participatory research with children and young people to explore placefeelings (for example, Thomson, 2008; Dennis, Gaulocher, Carpiano \& Brown, 2009; Pyyry, 2013) Taking photographs as a mode of communication can offer young people who may be marginalised an alternative visual language and offer the possibility of making their perspectives more 'visible'. According to Back $(2009$, p.474) a photograph taken is a representation of thought processes that can only with great difficulties be described through language. Through this representation, a link between the researcher and the world of the subject of research can be established and provide further avenues for discussion.

The pilot focused on adapting visual, participatory methods developed by Alison Clark and Peter Moss in relation to gathering place-meanings from children and staff in early childhood care and education environments (Clark \& Moss 2001, 2011; Clark 2010; Clark, 2011). This approach is designed to be multi-method and polyvocal. Following a period of observation, participants are offered a range of different modes of communication, including photography, to explore what it is like to be in a particular environment. The 
perspectives of different members of a community, whether children or adults, can be then set alongside each other and discussed and analysed. The main methods chosen for meaning-making in this pilot study were group discussion, photography and map-making.

\section{Preparing for fieldwork}

Consent was gained from the individual young people involved based on several initial visits and discussion. In developing this pilot study ethical consideration needed to be given to the specific characteristics of residential children's homes and to the lives of young people living there ${ }^{i}$. An important factor here was the recognition that most residents are not in residential child care by choice. It had to be assumed that the young people living in the pilot home did not necessarily see this home as their 'home' or that their perception of what 'home' means may be very fragile. Under these circumstances it was important to adopt a sensitive approach, respectful of young people's wishes to be engaged or not in the pilot and to the potential negative impact of another intrusion on their privacy and time.

During the first visit, which took place after school, the researcher introduced the project and himself to the four young people who were resident at the time of fieldwork. Through informal question and answer over dinner, a two-way process of observation took place between the researcher and the young people in the context of the residential care home. Young people, for example, asked the researcher questions about his experience of employment in a residential care home in another country. Through this initial observation young people could make first assumptions about the researcher which could lead to the build-up of a necessary level of trust. The researcher was also able to identify the least obtrusive periods of the day in which to invite the young people to take part in the study.

Although all four residents expressed enthusiasm for the project, in the event only two, Adam and Sylviai ${ }^{i i}$ took their own photographs. Staff members were supportive of the study but only one member of staff chose to take her own photographs.

\section{Fieldwork}

There were five fieldwork visits during which the researcher took field notes during and immediately after fieldwork sessions, and recorded some details about the young people who elected to take photographs. Adam, age 11, had been resident for three months on an interim basis, and was hoping to go to a boarding school. He was very positive about the residential home and the staff. Adam was very knowledgeable about institutional rules, especially about the reward system which included awarding money for attending school and for good behaviour. He explained these rules to other residents. On one occasion he made staff aware of a mistake they made when they gave education money to one of the girls even though this money should only be spent together with a member of staff. Sylvia, age 13 , came across as being very open and communicative about living in the home, but quickly lost interest in concentrating on the project or was busy doing other things. She had a wide range of interests and a lively social life. She also told the researcher that she really liked the staff team, enjoyed going to school and had friends there. She had been living in the home for approximately six months. 
Both Adam and Sylvia were invited to take photographs of anything that they thought represented what it meant to live in the home. A printer was available so the young people could print out their images immediately. The next stage of the activity was for the young people to choose ten of their photographs to create a map or poster. Whilst they were taking the images and creating the maps, the researcher asked questions and took notes about the young peoples' explanations for taking the images and the selections they made in composing the maps.

Taking the pictures became part of building rapport between the researcher and the young people. The camera and the creative process of taking photos became the 'common third' (Thempra, 2012) that linked the young person and the researcher through activities like explaining the camera, looking at pictures, printing them out or transferring them into the computer. This rapport was essential to building the trust needed to enable the young people to share their perspectives.

Staff members were also asked to imagine what it would be like to live in the home as a young person, through discussion with the researcher, taking photographs and making a map. In principle, all team members were supportive of the project but in the event only one member of staff, Pat, took photographs. She also agreed to make a map but was interrupted by a group of young people making a noise and did not have an opportunity to resume the task. [We have included her photographs and discussion in this analysis].

In summary, the data sources for the project were: i) fieldnotes recording initial discussions with young people and staff to introduce the project and find out about each other; ii) 28 photographic images from two young people and one member of staff; iii) recorded comments on each image; iv) two maps or posters created by arranging ten selected photographs to represent their view of the space and place.

The data was assembled in stages. First, a report of the research process was compiled, combining the researchers' impressions of each visit and each interaction with a detailed account of the photographic images and the recorded commentary on each photograph. Table 2 is an extract from the table recording Adam's comments ${ }^{\mathrm{iii}}$. 


\begin{tabular}{|ll|}
\hline Picture & Comments \\
\hline $\mathbf{2}$ & $\begin{array}{l}\text { Shows Mxxx (Staff member). Without staff there would be no [name of home]. The } \\
\text { people here are important they are what makes this a home. They are really nice and } \\
\text { they help us to do what we like. Sometimes they don't and they can be annoying. I like } \\
\text { most of them. }\end{array}$ \\
\hline $\mathbf{3}$ & $\begin{array}{l}\text { This is the kitchen. Staff cook our food here. We spend a lot of time here and it is really } \\
\text { nice that we can have something to eat when we ask. We have a menu that we can } \\
\text { choose from and there is a list with stuff on it which we can tick when someone goes } \\
\text { shopping. }\end{array}$ \\
\hline $\mathbf{4}$ & $\begin{array}{l}\text { My helicopter. I bought it from my education money. I can do a lot of tricks with it. } \\
\text { in my room at night. I would really like the light in my room to be off at night as it is } \\
\text { really bright when it is dark in the room. I do not know why this has to be on all the } \\
\text { time. }\end{array}$ \\
\hline
\end{tabular}

Table 2 Data extract recording Adam's comments on photographs taken.

The second stage was to prepare for analysis. Researchers compiled a second table (see Table 3), documenting the participants' comments, the researcher's description of the image, and the concepts and themes at work in each participant's text. These tables, which effectively coded the data, were the subject of extensive research team discussion, bringing together the team's expertise in residential care, the particular home and the data collection there, visual participatory methods and the Mosaic approach methodology.

\begin{tabular}{|c|c|c|}
\hline $\begin{array}{l}\text { Photographs } \\
\text { taken by } \\
\text { Adam }\end{array}$ & Adam's comments about the images & $\begin{array}{l}\text { Concepts and themes identified in the } \\
\text { text }\end{array}$ \\
\hline 5 & $\begin{array}{l}\text { I have drawn this. I can do really good } \\
\text { gratifies. This picture is hanging on door } \\
\text { to my room. }\end{array}$ & $\begin{array}{l}\text { Gateway to the private area of bedroom, } \\
\text { asserting the personal within the } \\
\text { institution. A sign of self/individual } \\
\text { existing } \\
\text { Sense of achievement and self- } \\
\text { worth/skills }\end{array}$ \\
\hline 6 & $\begin{array}{l}\mathrm{C} \text { [name of resident]. She is not here } \\
\text { right now. I really like her. }\end{array}$ & $\begin{array}{l}\text { Appreciation of the relational } \\
\text { possibilities within the institution }\end{array}$ \\
\hline 7 & $\begin{array}{l}\text { A poster of cars. I do not know who did } \\
\text { put it up, but I like cars so I took a } \\
\text { picture of this poster. }\end{array}$ & $\begin{array}{l}\text { Décor } \\
\text { Lack of knowledge about history of } \\
\text { décor. Is it knowledge of history of décor } \\
\text { that provides meaning? } \\
\text { Institutional framing of décor? }\end{array}$ \\
\hline 8 & $\begin{array}{l}\text { The dinner table. Here we sit and have } \\
\text { meals together. Sometimes we also just } \\
\text { sit and talk. }\end{array}$ & $\begin{array}{l}\text { Relational context of food and time } \\
\text { ('we sit' is a very social pedagogic } \\
\text { phrase conveying 'being together with } \\
\text { authenticity and meaning invested' - } \\
\text { much more than just sharing space) }\end{array}$ \\
\hline 9 & $\begin{array}{l}\text { The neighbours' geese. They are not } \\
\text { really important and we sometimes try } \\
\text { to feed them. They can be quite nasty. }\end{array}$ & $\begin{array}{l}\text { Boundaries of space - within which } \\
\text { defines our and your space }\end{array}$ \\
\hline 10 & $\begin{array}{l}\text { A poster of some gangsta rappers. I like } \\
\text { hip hop and I like skating. Listen to a lot } \\
\text { of rap music. }\end{array}$ & $\begin{array}{l}\text { Asserting the personal within the } \\
\text { institution } \\
\text { Enjoyment }\end{array}$ \\
\hline
\end{tabular}

Table 3 Data extract with participant's description of photographs and research team interpretation of concepts and themes.

\section{Findings from the research material}

The first step in data analysis was to conduct a thematic enquiry into the images recorded in the photographs (Table 4). Leading from the literature on residential care, we divided 
the images into three categories i) images about the home as people and relationships; ii) images about the home as material space as represented through images of objects; and iii) images of both objects and people.

\begin{tabular}{llll} 
Person & Images of people & Images of objects & Images of people and objects \\
Adam & 3 & 8 & 0 \\
Sylvia & 2 & 8 & 2 \\
Pat (Staff member) & 0 & 5 & 0 \\
Total & 5 & 21 & 2 \\
\hline
\end{tabular}

Table 4 Total images divided into three categories: people, objects, both people and objects.

Although there were images of people $(n=5)$, the majority of the images were of objects (21). Two were of both objects and people. What is notable in the commentary is how often the images of objects provoked discussion that was about the relational dimension of living in the home. Here we discuss our interpretation, based on the literature on home and institutional spaces, of three images of objects. We propose that these images can be seen as representing the residential home in three ways: institutionalised home, home as practices; and idealised home.

a) Institutionalised home

The image shows a dark space with an oval light in the centre of the lower third of the image. No other details are visible in the room. This image was taken by Adam and chosen as one of the ten images he selected to include on his poster of what it was like to live in the residential home. He gave the following account of this image:

These lights are everywhere. The green light on the side is on all the time even the one in my room at night. I would really like the light in my room to be off at night as it is really bright when it is dark in the room. I do not know why this has to be on all the time.

Adam's comment reveals one of the discomforts of living in a building that is designed as an institutional rather than a domestic place. Overhead lights are fitted to comply with health and safety requirements in order to maintain a light source at all times. This could be interpreted as necessary for a sense of protection but could equally be regarded as a form of surveillance. This results in bedrooms that cannot be completely dark at night and where residents are not in control of the level of light. This lack of control is an important distinguishing feature of home as institution. 
Adam does not appear to be aware of why this continuous light source is necessary as his comment indicates: 'I do not know why this has to be on all the time'. This comment reveals a sense of an unknown history that refers to objects, practices and places. The unknown history in this case refers to the object, the light source, and to the practice, the need to keep all rooms illuminated, including places such as bedrooms. Other images and comments revealed further examples of this unknown history. Adam chose, for example, to include a photograph of a poster of cars to discuss what it is like to live in the residential home. He commented: 'A poster of cars. I do not know who did put it up, but I like cars so I took a picture of this poster.' This unknown history of objects can be seen as a distinguishing feature of the 'institutional home'. The provenance of these objects are unknown and unnamed by residents in contrast with objects in a domestic setting where the provenance of objects may well be more readily familiar and known to inhabitants.

\section{b) Home as practices}

This image, taken by Adam, is a close-up photograph of the dining room table. The bottom edge of the rectangular table fills the lower edge of the photograph and shows the full length of the table surrounded by eight chairs stretching into the top third of the image. Patio doors are shown behind the top edge of the table. The table is clean and the surface is empty of objects. Adam's comment about the image is:

The dinner table. Here we sit and have meals together. Sometimes we also just sit and talk.

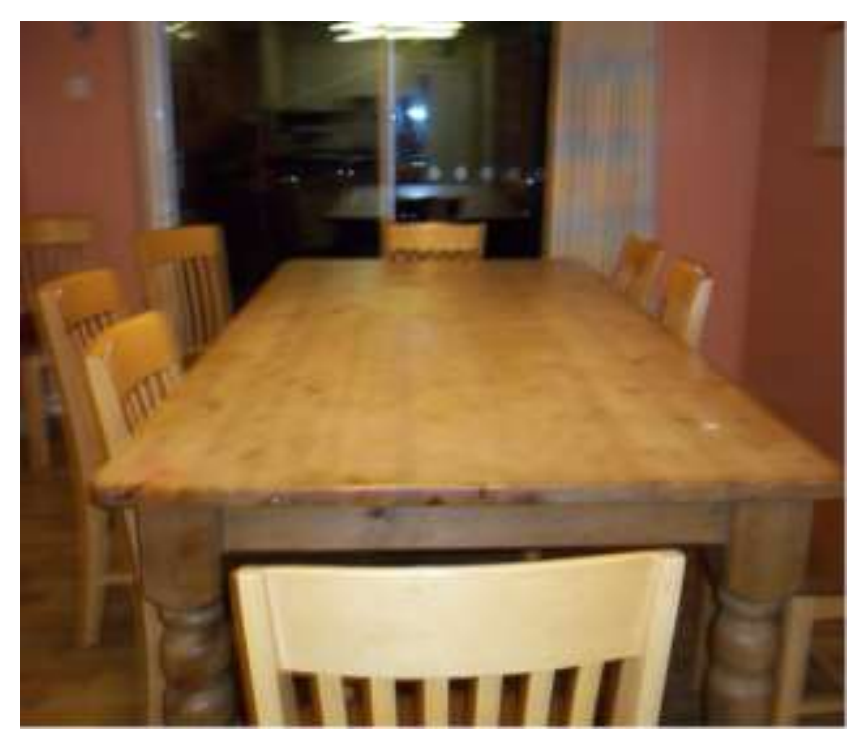

Figure 2 Close up of the dining table.

Here Adam has chosen a piece of furniture that appears to play a key role in the practices associated with the residential care home. It is where communal meals take place but it also has a role beyond food routines as a gathering point in the home where people communicate with each other. These conversations took place between residents and between residents and staff. This was indicated through observations and reinforced by an image taken by a member of staff with the following caption:

The kitchen and the lounge were purposely built to be the centre of the house. This is where almost everything happens. It is our meeting place. The large table is great when we sit here together with the young people.

The table was the meeting place and symbolised 'doing home', by drawing attention to the practices that happen there. This conveys a close association between home and functionality. This home is about routines that are of the moment, rooted in the present. This may be linked to the notion of institutionalised home as a place of unknown histories, as discussed above. Devoid of past memories associated with objects and place, life in a residential care home is a form of 'itinerant domesticity' focusing on constructing a sense 
of place in the present. This functionality can be expressed through drawing attention to what happens where. Two of the young people, for example, described the practices associated with choosing food. Sylvia took a photograph of the inside of the fridge and explained:

Our fridge with all the food in there. Very important because we have to eat. If we do not eat we die. I like that the fridge is full most of the time. There is a ticklist of all the things that should be in the fridge and when these are not there anymore we just tick the thing on the list and someone will buy it on their next shopping trip.

c) Idealised home

Figure 3 is an image taken by Pat when asked to imagine what it would be like to live in the residential home. The dominant object is a sideboard that takes up the lower half of the image. The sideboard is covered in different objects including two tall plants, a couple of large sweet tins and a fruit bowl. On the wall is a notice board and the edges of two pictures. Pat drew attention to the plants and the fruit bowl in her comment on the image:

Having plants in the house is what you would have at your own home. We always have fruits and vegetables available for the young people.

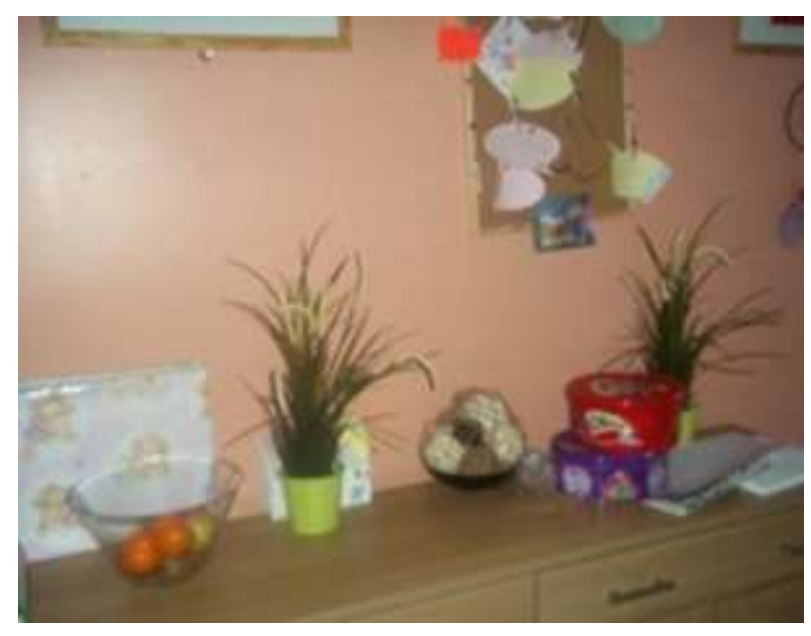

Figure 3 The sideboard.

There is an assumption in this explanation of what a 'normal' or idealised home should contain. A parallel is drawn between the décor of the residential care home and the member of staff's own home. Natural living objects are seen as part of this idealised home. The fruit bowl becomes another icon of home. This is a 'still life' of home, the subject of many paintings of domestic scenes. Pat's comment also implies another meaning. There appears to be an educational element to drawing attention to this object. It is seen as part of a discourse on healthy living, improving the diets of the young people living in care. One question this theme raises is whose 'idealised home' is represented within these shared institutional spaces?

A sideboard and fruit bowl might be component parts of a member of staff's home but not necessarily recognised as features of home by the young residents.

The one image of the fruit bowl can draw attention to each of the three themes identified here. It could be part of a narrative of 'institutionalised home', part of the responsibility of providing for the needs of the young people; it demonstrates the practices of 'doing home' and also highlights an underlying narrative of 'idealised home'. This overlapping of themes expresses the ambiguities of establishing a 'sense of home' in these environments that straddle domestic and institutional boundaries. 


\section{Conclusion}

This pilot project aimed to explore what 'place' meant to young people and staff in a children's home through adapting the Mosaic approach, a method widely known in the field of early childhood care and education, to older age groups and in a residential setting. The methodological task here merits a moment of critical reflection. Although superficially similar (care in early childhood and in children's residential care are both institutional settings), the environment of the care home produced some rather different considerations. The techniques used in the Mosaic approach of tours, photography and map or poster making required periods of concentration within the residential home that was not a space associated with such activities - activities perhaps more associated with educational or school-like spaces. This may be a reason why two of the residents did not take photographs although they expressed interest in the project. The project was most successful with the youngest resident, who had been there for a short while and was still coming to terms with his situation. He gave his mother a copy of his map 'so she knows where I am' and enjoyed learning the computer and printing skills required to make the map. The reasons why more staff members did not take part in the project may also be to do with the association of particular activities with particular spaces; visual and/or creative methods are not part of the usual repertoire of self-expression in residential care work while the verbal discussion required for interviews is. Overall, the pilot project showed that the use of photography and annotated images opens up unanticipated areas for analysis that may be particularly important for understanding the range of perspectives held by young people and staff.

In relation to a sense of residential care place as home, the paper has discussed the ambiguities and ambivalences of home within institutional spaces both over time in residential child care and across different settings such as domestic homes and residential care for older people. Understandings of 'home' suggest that the physical environment is only one dimension of creating 'home'; dimensions of time and continuity, choice of objects on display and the meanings attached to objects are also important. The profiles of residents in children's homes and the analysis of images taken by pilot project participants showed that creating a space that was homelike, to which they might sense they belong, although desirable in policy, is highly complex. Young people are likely to have had fractured senses of home before arriving in a residential placement. They enter a space that is predefined by external institutional requirements and with little or no provenance in the objects on display that might reinforce their identification of the space as 'theirs'. The images and objects discussed highlighted the institutional - the constant light, a poster belonging to an unknown person, a fridge filled via a ticklist - but also demonstrated the ways in which objects facilitate discursive and educational opportunities - the table as focal point for talking, house plants to emulate 'home', and the fruit bowl for promoting a healthy diet.

In many ways the 'home' practices reported in this paper support and extend the previous findings regarding the ambivalent sense of place in residential care. First, there is the question of 'whose home'? Is it for the young people, or organised with the staff's needs in mind? Our analysis supports that of Dorrer et al. (2010) in drawing attention to three spaces in residential care: home, workplace and institution, but extends notions of 'home' 
and relates this to more general understandings of home, and by doing so ownership of the space is revealed to be uncertain.

The second question we highlight is 'How do we do home?' What practices are employed to generate a sense of home in children's residential care? We have seen different ways of 'doing home' identified by young people and staff, including practices that relate to food and eating together. The practices identified were focused in the present, were functional and closely tied in with supporting relationships. This present orientation highlighted the lack of history associated with the particular environment. The young people were involved in constructing a sense of home and a sense of place rapidly without deep connections to the physical appearance or established rules. This appears to require an intense or concertinaed building up of ways of doing home. Members of staff are also engaged in a parallel process of how to construct such a place. This can be unscripted and requires further research to understand as regulations imply but do not make explicit how to 'do' home.

\section{End Notes}

Alison Clark, Senior Lecturer, Department of Childhood, Youth and Sport, Faculty of Education and Language Studies The Open University, Milton Keynes. Claire Cameron, Reader in Education (Corresponding Author), Thomas Coram Research Unit, Institute of Education University of London, 27/28 Woburn Square, London WCIH OAA. Stefan Kleipoedszus is and independent researcher and Social Pedagogue.

\section{Acknowledgements}

The research team is indebted to the young people and staff of the residential children's home and to Quarriers Charity for their cooperation. The research team benefited from collaboration with colleagues at the University of Strathclyde. The study was funded by the Faculty of Health, Social Care and Education, Anglia Ruskin University and by The Open University. There are no known conflicts of interest for any of the co-authors with the funders of or the participants in the study.

i Permission to conduct the study was given via the Anglia Ruskin University Research Ethics Sub-Committee before fieldwork began.

ii All names are pseudonyms

\section{References}

Back, L. (2009). Portrayal and betrayal: Bourdieu, photography and sociological life. The Sociological Review, 57 (3), 471-490.

Berridge, D., Biehal, N. and Henry, L. (2012). Living in children's residential homes: Research report (DFE-RR201). London: Department for Education.

Cameron, C., Petrie, P., Wigfall, V., Kleipoedszus, S. and Jasper, A. (2011).Final report of the social pedagogy pilot programme: development and implementation. Thomas Coram 
Research Unit, Institute of Education, University of London http://eprints.ioe.ac.uk/6767/1/Cameron2011Final(Report).pdf

Clark, A. \& Gallacher, L. (2013). Children in and out of context. In A. Clark (Ed.) Childhoods in Context. (pp. 1-42). Bristol: Policy Press.

Clark, A. and Moss, P. (2011). Listening to young children: the Mosaic approach. (2 ${ }^{\text {nd }}$ Ed.). London: National Children's Bureau.

Clark, A. (2010). Transforming children's spaces: Children's and adults' participation in designing learning environments. Abingdon: Routledge.

Clark, A. (2011). Breaking methodological boundaries? Exploring visual, participatory methods with adults and young children. European Early Childhood Education Research Journal, 19 (3) 321-330.

Clough, R., Bullock, R. \& Ward, A. (2006). What works in residential child care: A review of research evidence and the practical considerations. London: National Children's Bureau.

Das, V., Ellen, J.M., \& Leonard, L. (2008). On the modalities of the domestic. Home Cultures, 5 (3), 349-372.

Dennis, S., Gaulocher, S., Carpiano, R. \& Brown, D. (2009). Participatory photo mapping (ppm): Exploring an integrated method for health and place research with young people. Health and Place, 15 (2), 466-473.

Department for Education (2011). Children's homes: National minimum standards. Retrieved from https: / /www.education.gov.uk/publications/eOrderingDownload/NMS\%20Children's\%20Ho mes.pdf [accessed 27 May 2014]

Dorrer, N., McIntosh, I., Punch, S. \& Emond, R. (2010). Children and food practices in residential care: Managing ambivalence in the institutional home. Children's Geographies, 8(3), 227-232.

Feininger, A. (1965). Die neue Foto-Lehre. Düsseldorf: Econ (Das moderne Sachbuch, 32).

Foster, P. (2006). Observational Research. In R, Sapsford \& V. Jupp (Eds.), Data collection and analysis. (2nd Ed.) (pp. 57-92). London: Sage.

Holland, S. \& Peace, S. (1998). Homely residential care: The report of a pilot study of small homes for older people carried out in Bedfordshire, Buckinghamshire and Hertfordshire during 1995. Milton Keynes: The Open University.

Hurdley, R. (2006). Dismantling mantelpieces: Narrating identities and materializing culture in the home. Sociology, 40, (4) 717-733.

Jack, G. (2010). Place matters: The significance of place attachments for children's wellbeing. British Journal of Social Work, 40, 755-771. 
Kahan, B. \& Banner, G. (Eds). (1969). Residential task in child care: the Castle Priory Report. Banstead: Residential Care Association.

Kahan, B. (2000). Swings \& roundabouts in child care policy \& practice fifty years 1948 1998. Paper given at the inaugural conference of the Association of Child Abuse Lawyers, Cambridge University, 1999. Retrieved from http://www.davidlane.org/children/chukapr/mar2000/bkspeech.htm

Kornerup, H. (Ed.) (2009). “Milieu Therapy" with children: Planned environment therapy in Scandinavia. Lejre: Forlaget Perikon.

Lane, D. (2010). Family group homes, child web mag, June. Retrieved from http://www.childrenwebmag.com/articles/child-care-history/family-group-homes

Maier, H. (1987). Developmental group care of children and youth: Concepts and practice. Binghamton: The Haworth Press.

Mallett. S. (2004). Understanding home: A critical review of the literature. The Sociological Review, 52(1), 62-89.

Massey, D. (2005). For space. London: Sage.

Milligan, C. (2003). Location or dislocation? Towards a conceptualization of people and place in care-giving experience. Social and Cultural Geography, 4 (16), 455-470.

Milligan, C. (2005). From home to home: Situating emotions within the caregiving experience. Environment and Planning A, 37(12), 2105-2120.

Morgan, R. (2009). Life in children's homes: A report of children's experiences by the Children's Rights Director for England. London: Ofsted.

Moss, P. \& Petrie, P. (2002). From children's services to children's spaces: Public policy, children and childhood. London: Routledge Falmer.

National Institute for Health and Clinical Excellence (2010). Promoting the quality of life of looked-after children and young people, NICE public health guidance 28. Retrieved from: http://publications.nice.org.uk/looked-after-children-and-young-people-ph28

Peace, S. \& Holland, C. (2001). Homely residential care: A Contradiction in terms? Journal of Social Policy, 30 (3), 393-410.

Pyyry, N. (2013). Sensing with' photography and 'thinking with' photographs in research into teenage girls' hanging out. Children's Geographies, DOI:

10.1080/14733285.2013.828453.

Schultheis, F., Holder, P. \& Wagner, C. (2009). In Algeria. Pierre Bourdieu's photographic fieldwork. SCALA Discussion Paper No. 12/2009, University of St. Gallen.

Smith, M. (2009). Rethinking residential child care: Positive perspectives. Bristol: Policy Press. 
Steckley, L. (2012). Touch, physical restraint and tTherapeutic Containment in Residential Child Care. British Journal of Social Work 42, 537 - 555.

Thempra (2012). The common third. Accessed $27^{\text {th }}$ May 2014 http://www.thempra.org.uk/concepts_c3.htm

Thomson, P. (Ed.) (2008). Doing visual research with children and young people. London: Routledge.

Tuan, Y-F. (1977) Space and Place: the perspective of experience. Minneapolis: Minnesota University Press.

Varley, A. (2008). A place like this? Stories of dementia, home and the self. Environment and Planning D, Society and Space, 26, 47-67.

Young, I. M. (1997). Intersecting voices: dilemmas of gender, political philosophy and policy. Princeton NJ: Princeton University Press. 